\title{
Nivel de precios y actividad económica: comparaciones regionales en el Virreinato del Perú (siglos XVI-XVII)*
}

\author{
Héctor Omar Noejovich \\ Pontificia Universidad Católica del Perú \\ hnoejov@pvcp.edu.pe
}

\begin{abstract}
Resumen
Este trabajo es un análisis cuantitativo sobre la base de las cifras disponibles, y descansa en una metodología estadística para discutir, esencialmente, la hipótesis de la "crisis del siglo XVII".
\end{abstract}

Palabras clave: Perú, siglos XVI-XVII, historia económica, precios.

\begin{abstract}
This paper deals with quantitative analysis from figures available. The approach relies on statistics methodology and discusses, essentially, the hypothesis on "17th's crisis".
\end{abstract}

Key words: Peru, 16th and 17th centuries, economic history, prices.

\section{Introducción}

Este trabajo es un peldaño más en una línea de investigación emprendida hace algunos años (Pease y Noejovich; Noejovich, "La economía" y "El consumo"; Salles y Noejovich "Santiago"). El derrotero que nos hemos señalado es brindar una imagen de la economía del Virreinato del Perú bajo la égida de los Habsburgo.

¿La razón del periodo seleccionado? Dicho periodo representa una coyuntura histórica, donde la articulación entre América y España tuvo características más o menos homogéneas, como fue servir a los intereses hegemónicos mundiales de los Austrias.

* Este artículo se deriva de la ponencia presentada al "Primer Congreso Internacional de Peruanistas en el Extranjero" (Universidad de Harvard, Boston, 29 de abril-1 ${ }^{\circ}$ de mayo, 1999). 
La esencia de este ensayo estriba en la elaboración estadística de indicadores disponibles. Aun cuando en los trabajos antes citados el lector encontrará una información detallada de las fuentes y procedimientos utilizados, presentaremos a continuación un breve resumen.

\section{Fuentes}

1. Las cartas-cuentas, provenientes de las cajas reales, según fueron publicadas por TePaske y Klein. Estas fueron elaboradas contablemente en Pease y Noejovich, donde se diferencia entre ingresos fiscales, movimientos financieros y extraordinarios ${ }^{1}$. El periodo considerado comprende entre 15801714.

2. Para los precios hemos utilizado el excelente trabajo de Pablo Macera, que reúne información de archivo desde 1560, tanto para Lima como para el resto del territorio peruano actual. En el caso de Chile, las series provienen de De Ramón y Larraín ("Orígenes" 406, 407)2. También hemos incluido los precios de Pardo para Nueva Granada ${ }^{3}$.

3. Los datos de acuñación provienen del trabajo de Lazo García, quien ha publicado con lujo de detalles las acuñaciones de las casas de moneda de Lima, y de Potosí, desde 1600, con base en fuentes documentales.

4. Los datos de producción de oro en Nueva Granada provienen de Lucena Samoral.

\section{Metodología}

La elaboración de indicadores estadísticos apunta a establecer órdenes de magnitud, parámetros dentro de los intervalos de confianza y la bondad del ajuste en las tendencias, medida en el coeficiente $R^{2}$, que nos muestra los grados de estabilidad de la serie en el tiempo.

Bajo esta tesitura, la imprecisión usual en los datos de este tipo se morigera en el universo estadístico y, especialmente, al ser las cajas reales un conjunto más o

Estamos de acuerdo con Klein sobre la importancia de estas fuentes, pero discrepamos en el sentido en que interpreta las cifras, toda vez que la clasificación de ingresos y gastos que realiza (121) mezcla conceptos contables de distinto origen, como aquellos que aquí se diferencian. A nuestro juicio, este es un punto crucial para la interpretación de esas fuentes. Para un detalle de nuestra clasificación, véase el Anexo II.

2 Este trabajo fue criticado y dio lugar a un acalorado debate entre Ruggiero Romano y De Ramón y Larraín ("Orígenes").

3 Esta información me fue suministrada por Carlos Newland, para ese entonces becario de la Fundación Guggenheim, en la Universidad de Harvard. 
menos homogéneo, se puede suponer la constancia en los sesgos de error y, por ello, obtener indicadores contrastables.

Así, los datos de actividad económica, precios, acuñación y producción de oro ${ }^{4}$ se cruzan entre sí y se aceptan para el caso de que muestren relaciones lógicas y sustentables en el contexto histórico. Las convenciones metodológícos establecidas para la elaboración se detallan en el Anexo I.

En especial, los indicadores de actividad económica funcionan como sustitutos de aquello que, modernamente, representan el PIB, ingreso nacional o producto nacional; en nuestro caso, serían, más bien, el producto global y/o volumen global de transacciones, y han sido construidos con los datos fiscales, conforme con el procedimiento que se indica en el Anexo II.

\section{El análisis}

Comenzamos por comparar la estructura de la actividad económica de las tres regiones, como se aprecia en la Tabla 1.

\section{Tabla 1. Actividad económica: Lima (1580-1714), Trujillo (1602-1712) y Santiago de Chile (1613-1714)}

\begin{tabular}{|l|r|r|r|}
\hline \multicolumn{1}{|c|}{ Rubro } & \multicolumn{1}{c|}{ Lima } & \multicolumn{1}{c|}{ Trujillo } & \multicolumn{1}{c|}{ Santiago } \\
\hline Comercio exterior & 17,9 & 7,1 & 23,4 \\
\hline Comercio interior & 44,0 & 35,9 & 29,8 \\
\hline Composiciones, arrendamientos y ventas & 0,3 & ---- & 0,3 \\
\hline Eclesiásticos & 24,9 & 46,1 & 39,3 \\
\hline Esclavos & ---- & ---- & 0,3 \\
\hline Estancos & ---- & 0,1 & 0,2 \\
\hline Indígenas y castas (tributo) & 4,4 & 8,1 & 0,9 \\
\hline Minería & 0,7 & 0,2 & 1,2 \\
\hline Oficio y afines & 7,5 & 2,2 & 4,0 \\
\hline Varios & 0,3 & 0,3 & 0,6 \\
\hline Total & $\mathbf{1 0 0 , 0}$ & $\mathbf{1 0 0 , 0}$ & $\mathbf{1 0 0 , 0}$ \\
\hline
\end{tabular}

* Esto puede parecer extraño, pero es menester insistir en que la información proviene de recaudaciones fiscales por "manifestaciones de esclavos". Esclavos introducidos por el puerto de Buenos Aires no pagaban manifestaciones. Probablemente, estuviesen gravados con alcabala, pero carecemos, por el momento, de mayor información al respecto.

Fuente: adaptado de TePaske y Klein.

4 Este último dato, para Nueva Granada, es tomado como indicador de la "oferta monetaria" en lugar de la acuñación. 
Las tres regiones se encontraban alejadas de los centros mineros principales, como los de Potosí, Porco y Oruro. El grueso de los ingresos fiscales y, por ende, de la actividad económica provenía del comercio, tanto interior como exterior. Los ingresos eclesiásticos, derivados principalmente del diezmo ${ }^{5}$, son indicadores de la actividad agraria, toda vez que el objeto gravado son las cosechas.

En el caso del comercio, en Santiago, aun sin ser el primer puerto de la "Armada de Sur", la significación del comercio exterior era superior a la de Lima; también la agrícola. Esto último corrobora su función de "granero de Lima" señalada en la historiografía. Trujillo, por supuesto, era una región predominantemente agrícola; como era de esperar, los "oficios y afines", que están relacionados con el ingreso de los funcionarios públicos, tienen un nivel más alto en Lima que en las otras dos ciudades (Figura 1).

\section{Figura 1. Actividad económica (tendencias). Lima (1602-1714), Santiago (1613-1714) y Trujillo (1602-1712)}

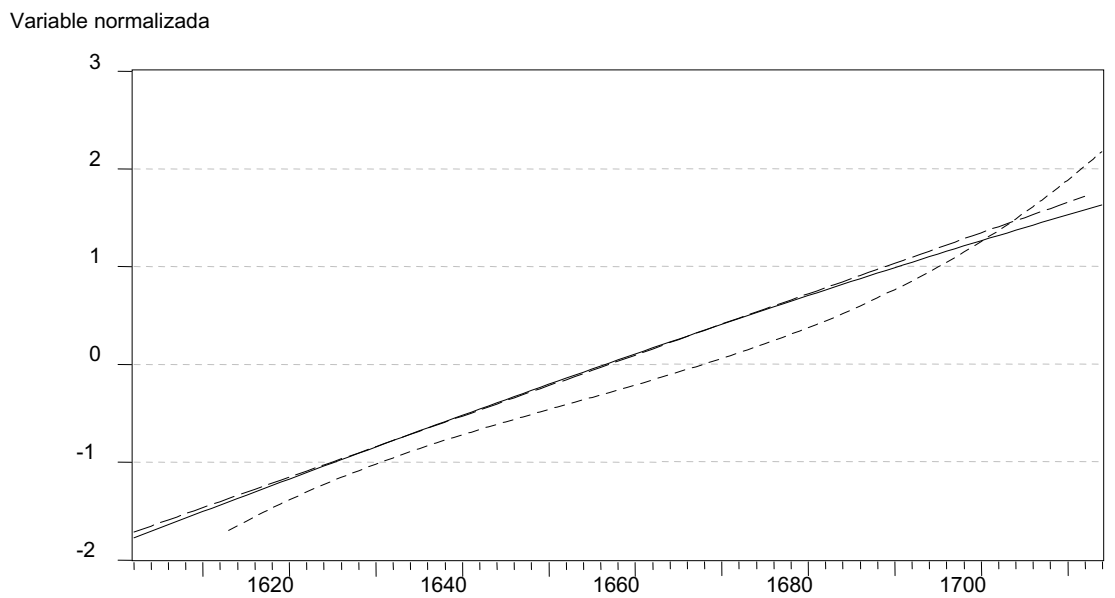

\begin{tabular}{|l}
\hline Lima \\
\hline
\end{tabular}

Fuente: TePaske y Klein; Salles y Noejovich “Santiago”, Pease y Noejovich, Noejovich (2001).

5 El origen de los diezmos como "décima parte de los productos" se remonta al Antiguo Testamento (Levítico 27:30-32; Deuteronomio 14:22; Números 18:25-30); posteriormente, se convirtieron en una prestación de los fieles a la Iglesia para el sostenimiento del culto. Escalona y Agüero (I 239) dicen respecto a los diezmos: "En esta conformidad, desde el principio de la Conquista, pusieron en ejecución la obligación de hacer templos, Iglesias, Catedrales y Colegios repartiendo los diezmos de tal manera, que reservando para sí los dos novenos" (cursiva mía). La Eximia Devotionis de Alejandro VI, en 1501, concedió a la Corona española los diezmos de las iglesias americanas. 
En los tres casos, la actividad económica ${ }^{6}$ fue creciente a lo largo del ciclo; se observó una aceleración en el caso de Santiago respecto a las otras dos regiones, en el último cuarto del siglo XVII, tal como se aprecia en la Figura 1.

La diferencia entre la aceleración de Santiago y la constancia en el crecimiento de Lima y Trujillo sugiere un mayor dinamismo en la primera, que analizaremos por medio de los movimientos de precios, como sigue a continuación (las figuras 2 y 3 comparan tendencias y fluctuaciones, respectivamente).

\section{Figura 2. Precios (tendencias). Lima-Santiago (1631-1714)}

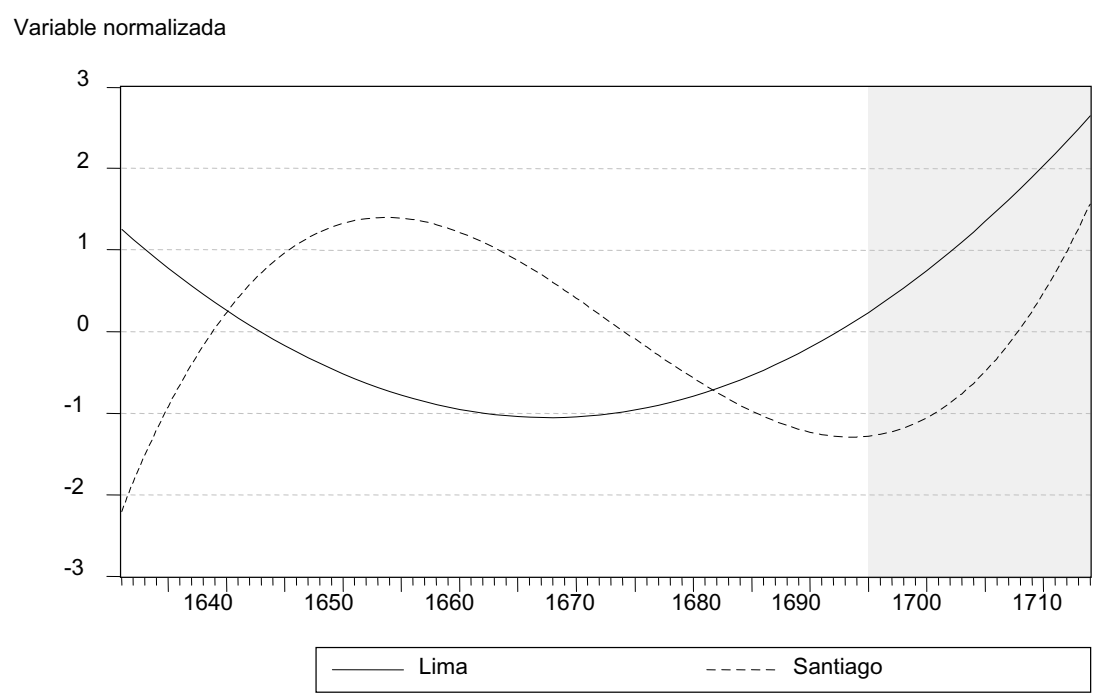

Fuente: adaptado de De Ramón y Larraín “Orígenes”; Noejovich (2001).

Respecto a la tendencia de los precios ${ }^{7}$, en el caso limeño, apreciamos una caída hacia la mitad del siglo XVII, que, desacelerándose, se vuelve creciente a partir de 1670, aproximadamente. Para Santiago solo podemos señalar, de momento, que el "pico" ascendente de la tendencia se ubica aproximadamente con la sublevación indígena de 1655 , que se invirtió casi al final del siglo y coincidió con la aceleración en el crecimiento de la actividad económica (Figura 1). Así mismo, es congruente con la modificación del Situado a partir de 1688, cuando se hace cargo de este la Caja Real de Potosí, en lugar de la Caja Real de Lima

Existe una alta correlación positiva Lim/Sgo $r=0,98 ; \operatorname{Lim} / \operatorname{Tru} r=0,99$.

7 La "bondad del ajuste" en los precios de Lima y Trujillo es más alta que en Santiago; esto puede atribuirse tanto a las metodologías de las fuentes, como a mayor o menor estabilidad en cada espacio. Desde esta perspectiva, las fluctuaciones santiaguinas serían más significativas que las limeñas. 
(Suárez 281); la diferencia estriba en que, en el primer caso, esa transferencia era mayormente en suministros ${ }^{8} \mathrm{y}$, por tanto, la nueva estructura dinamizó el mercado local con mayor afluencia de metálico.

\section{Figura 3. Precios (fluctuaciones). Lima-Santiago (1631-1714)}

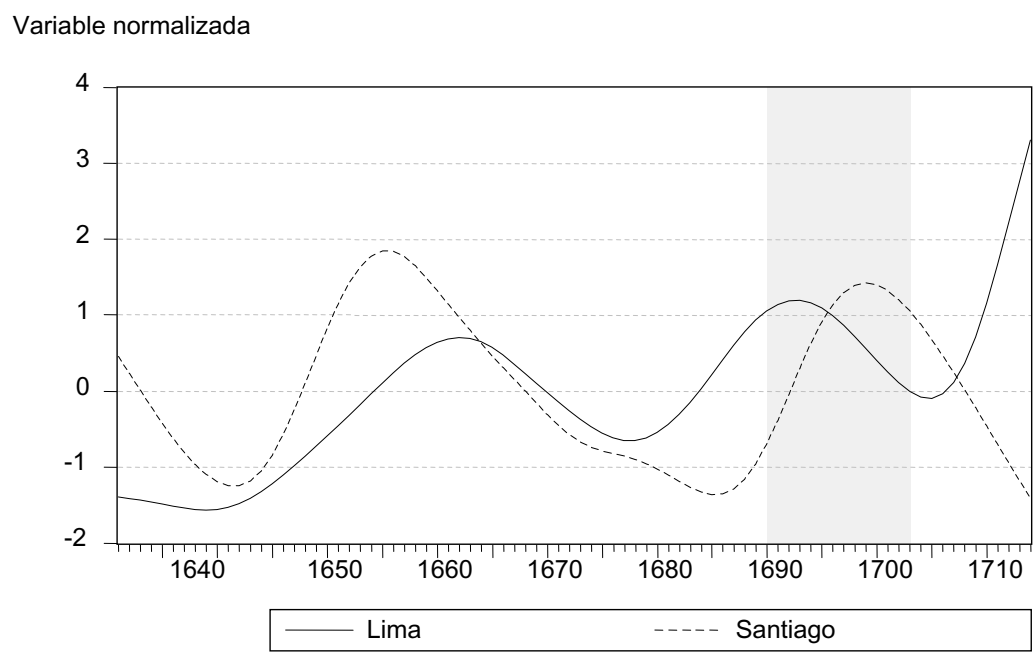

Fuente: adaptado de De Ramón y Larraín “Orígenes”; Noejovich (2001)

Pero la conexión entre los movimientos de precios entre ambas regiones se aprecia con mayor claridad en las fluctuaciones. En mi opinión, el tráfico con relación al Situado (Suárez 281) conectó los sistemas de precios; el compás de altas y bajas es similar. A partir de la modificación de la proveniencia de los situados que señalamos líneas más arriba, comienza a ser divergente y se acentúa desde comienzos del siglo XVIII, probablemente por la influencia del comercio francés, primero por medio de la Compañía de los Mares del $\operatorname{Sur}^{9}$ y luego con prácticamente la suspensión de las flotas durante la Guerra de Sucesión de España ${ }^{10}$ (Figura 4).

Según Vargas Cariola, solamente llegaba en efectivo un tercio del Situado.

9 Creada en 1698, con una participación del 25\% de la Corona (Malamud Rikles 71), sobre la base de incursiones comerciales anteriores, como la De Bauchesnes en 1697 (Walker 1979). Pero también incursionaron ingleses al amparo de un tratado de 1670 (Fernández Nadal 2006).

10 La única flota que atravesó el Atlántico fue la comandada por el Conde de Casa Alegre en 1706 (Walker, pássim). 


\section{Figura 4. Actividad económica (fluctuaciones). Lima-Santiago (1613-1714)}

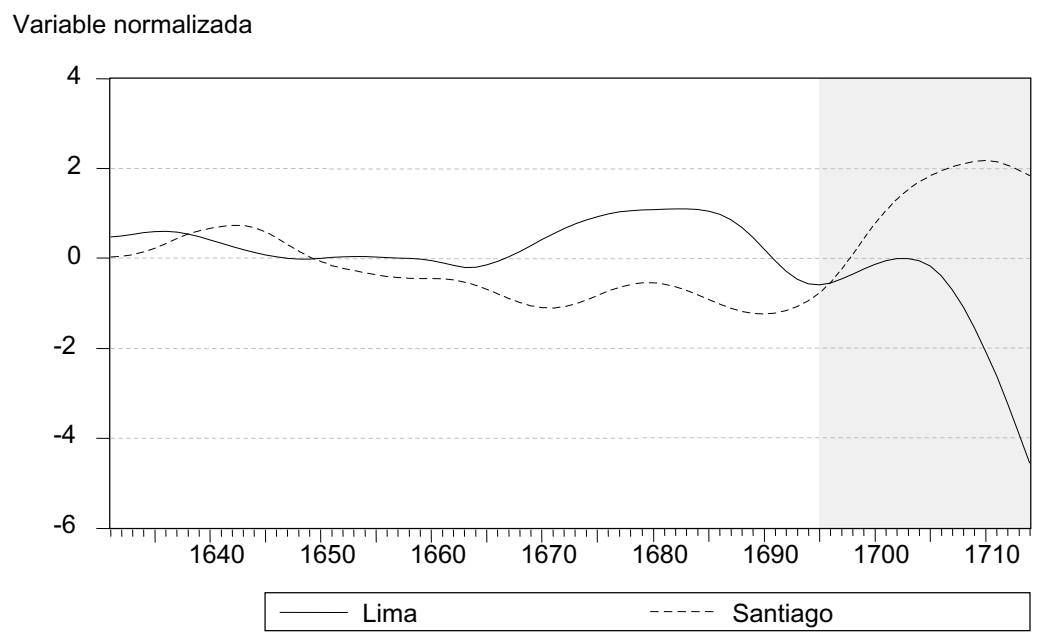

Fuente: Noejovich (1997), y Salles y Noejovich (“Santiago”).

Si vemos las fluctuaciones de la actividad económica, el patrón se repite hasta 1695, aproximadamente (Figura 4). La economía santiaguina parece haber dado varias señales de recuperación, a pesar de los desastres naturales y las rebeliones indígenas, apreciación corroborada en los índices presentados (Salles y Noejovich "Santiago"). Pero, además, debemos, nuevamente, enfatizar en que tanto la divergencia en los niveles de fluctuación de la actividad económica, como la convergencia en las tendencias, son congruentes con la modificación del Situado, del cual ambas economías - limeña y santiaguina - se "desconectaron", a fines del siglo XVII, al menos en los aspectos comerciales (Figura 5). 
Figura 5. Precios y déficit fiscal (tendencias). Santiago (1631-1714)

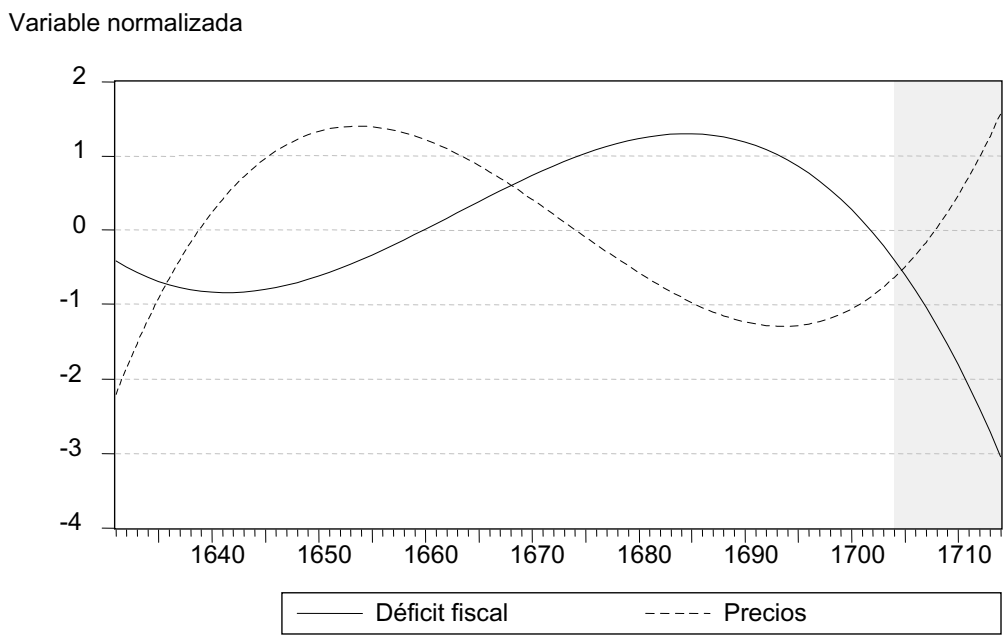

Fuente: adaptado de De Ramón y Larraín (“Orígenes”); Salles y Noejovich (“Santiago”).

Las tendencias inversas entre precios y déficit fiscal son, a mi juicio, representativas de la "carencia de fondos" de la Caja de Santiago (Figura 5). Por otra parte, el déficit fiscal crece después del terremoto de 1643 y la sublevación indígena de 1655 (Mellafe 276). Así mismo, la expansión de la tendencia de los precios y la contracción del déficit fiscal es congruente con las consecuencias de la Guerra de Sucesión de España, que ubicó a Santiago en una posición autónoma frente al monopolio comercial sevillano.

En términos de fluctuaciones, salvo para el periodo 1668-1692, se repite el mismo patrón inverso, lo que refuerza la interpretación monetaria: a mayor déficit fiscal, mayor carencia de fondos; ergo, caída de los precios (Figura 6). 


\section{Figura 6. Precios y déficit fiscal (fluctuaciones). Santiago (1631-1714)}

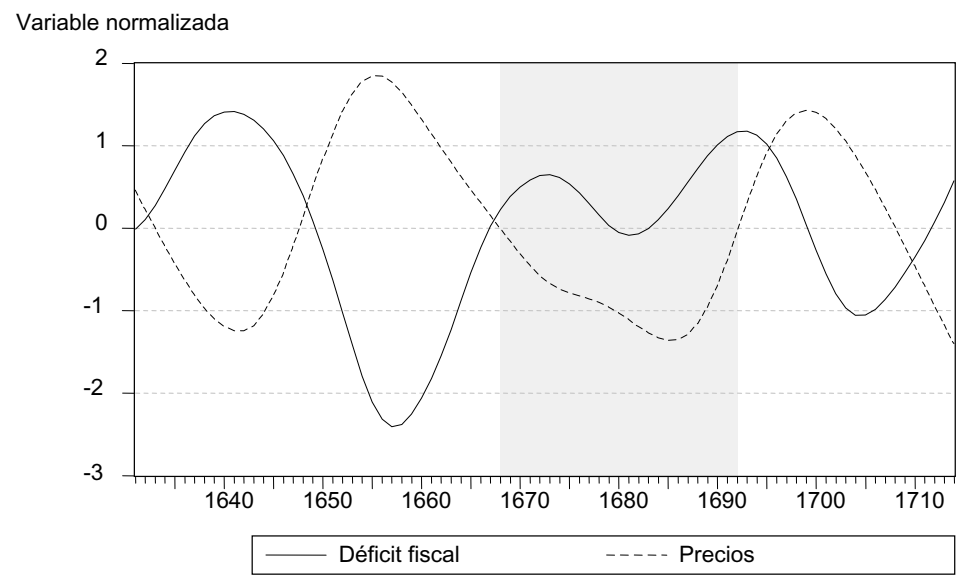

Fuente: adaptado de De Ramón y Larraín (“Orígenes”) y Salles y Noejovich (“Santiago”).

A la Caja Real de Lima le cupo el rol de "centro suministrador de fondos", tal como se aprecia en la Tabla 2. Para el caso de la relación financiera entre Lima y Chile obtenemos la cifra aproximada de treinta millones de pesos de a ocho remitidos como Situado ${ }^{11}$; un reflejo de esta dinámica y a la vez reveladora política financiera virreinal, lo podemos apreciar al comparar las remesas a España y Chile (Figura 7).

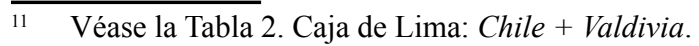


Tabla 2. Movimientos financieros. Entre cajas reales. Lima (1580-1714)

(Miles de pesos de a ocho)

\begin{tabular}{|l|r|r|}
\hline \multirow{2}{*}{ Caja } & \multicolumn{2}{|c|}{ Lima } \\
\cline { 2 - 4 } & \multicolumn{1}{|c|}{ Ingresos } & \multicolumn{1}{|c|}{ Egresos } \\
\hline Arequipa & 18,5 & \\
\hline Arica & 18,9 & $109.078,4$ \\
\hline Buenos Aires & 126,4 & $24.593,2$ \\
\hline Castilla & & 300,1 \\
\hline Chile & $228.136,7$ & 11,9 \\
\hline Córdoba & 17,3 & \\
\hline Cuzco & & $7.616,4$ \\
\hline De fuera & & \\
\hline Huancavelica & & \\
\hline La Paz & 2,0 & \\
\hline Lima & & $28.897,6$ \\
\hline Nueva Granada & $2.312,3$ & \\
\hline Oruro & & $5.109,8$ \\
\hline Panamá & & $175.607,4$ \\
\hline Paraguay & & \\
\hline Potosí & & \\
\hline Real Hacienda* & & \\
\hline Santa Fe & & \\
\hline Tucumán & & \\
\hline Valdivia & & \\
\hline Total & & \\
\hline
\end{tabular}

* En el periodo 1580-1591, para la Caja de Lima este ramo corresponde a las remesas a Castilla, como se denominó en las cartas-cuenta con posterioridad a aquél (Pease y Noejovich).

Fuente: Salles y Noejovich (“Santiago”).

\section{Figura 7. Remesas de la Caja de Lima a \\ Castilla y Santiago (1613-1714)}

Millones de pesos de a ocho

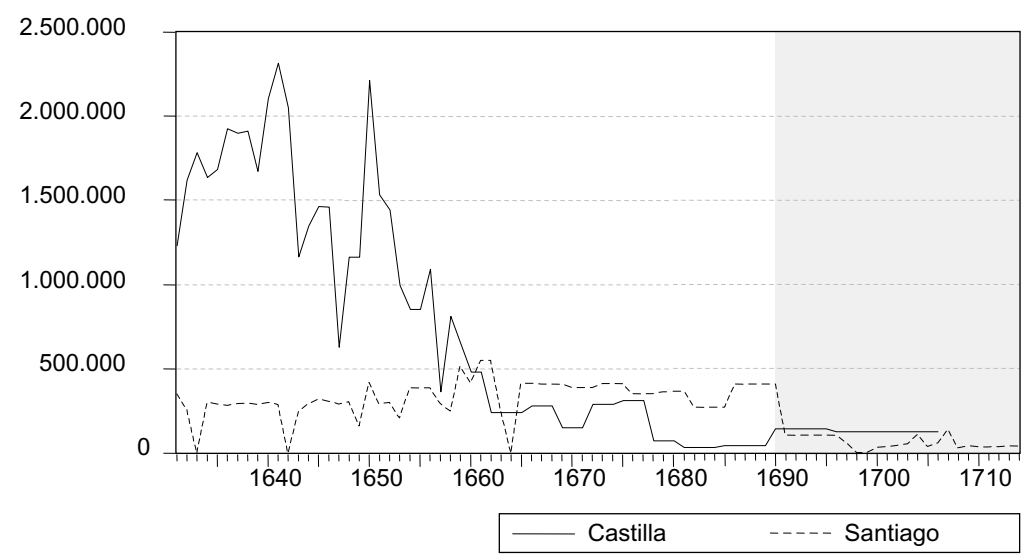

Fuente: Salles y Noejovich (“Santiago”). 
Esta situación es congruente con los cambios en la economía virreinal, derivados de la menor cantidad de plata registrada en las cajas reales, el cual hemos denominado como "fraude potosino" (Noejovich, "El consumo"). En efecto, tomando como referencia la producción, importación y exportación de azogue (Noejovich, "El consumo"), podemos concluir que la tan mentada "caída de la economía potosina" no fue realmente tal y, antes bien, dio lugar a la creación de "circuitos informales" alimentados por la "plata producida y no quintada" ${ }^{2}$.

Pero mientras tanto, ¿qué ocurría en Trujillo? Las cifras de las que disponemos de la región no nos permiten efectuar un análisis tan extenso, pero nos ubican en los finales del siglo XVII y comienzos del XVIII. Desde esta perspectiva, en la Figura 8 podemos apreciar una tendencia descendente de los precios en comparación con Lima ${ }^{13}$.

\section{Figura 8. Precios (tendencias). Lima-Trujillo (1688-1714)}

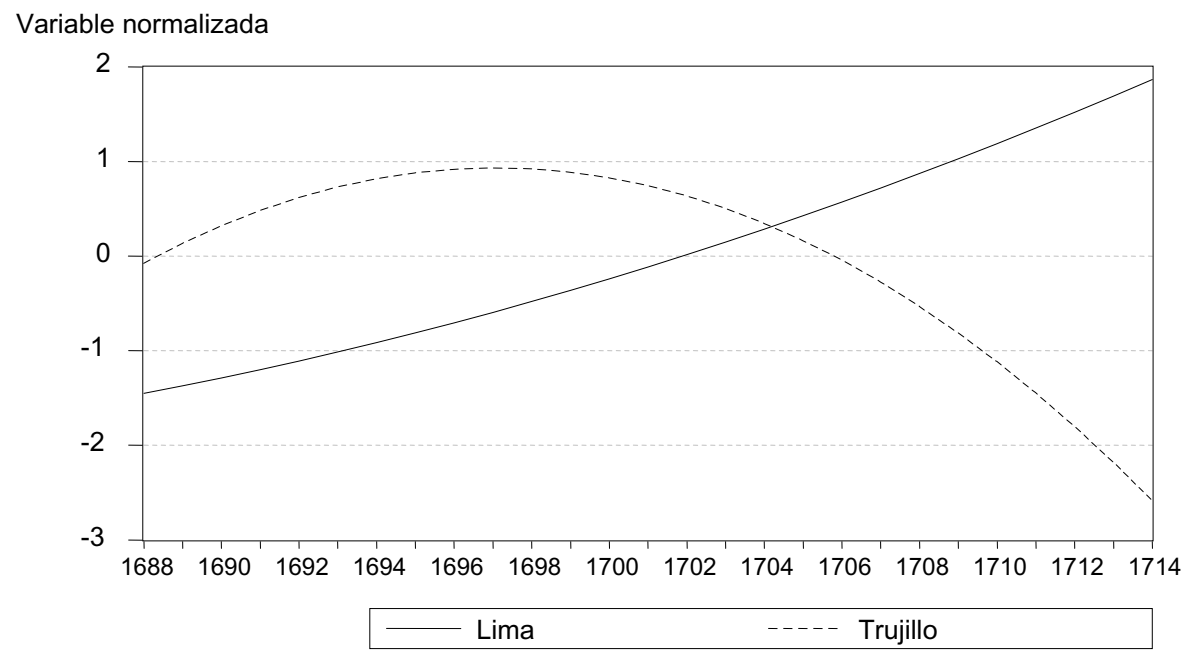

Fuente: adaptado de Macera y Noejovich (2001).

¿Qué lectura cabe? En parte, podemos hacer una inferencia de las distintas estructuras productivas (cf. supra, Tabla 1), en la medida en que Trujillo resultaba una región menos comercial que las otras aquí consideradas. Esa preponderancia

12 Por ejemplo, los circuitos señalados por Assadourian.

13 Somos conscientes de que, si bien el procedimiento es homogéneo, cuando se trabaja con series de datos de diferente elongación temporal, los resultados pueden distorsionarse. Un estudio más minucioso, ítem por ítem, previsto en nuestro plan de investigación, permitirá ahondar sobre el particular. Por ahora es todo lo que podemos ofrecer. 
agraria, con unidades de producción formadas por haciendas e indios tributarios, orientadas más al autoabastecimiento que a la mercantilización, constituye una hipótesis plausible.

Las fluctuaciones inversas de precios y actividad económica también son consistentes con la hipótesis indicada (Figura 9). Dentro de una estructura productiva, que no está orientada al mercado, parece lógico suponer que un alza de precios tenga un efecto depresivo, toda vez que representa un mayor costo de los insumos no producidos internamente, y viceversa.

\section{Figura 9. Actividad económica y precios (fluctuaciones). Trujillo (1688-1712)}

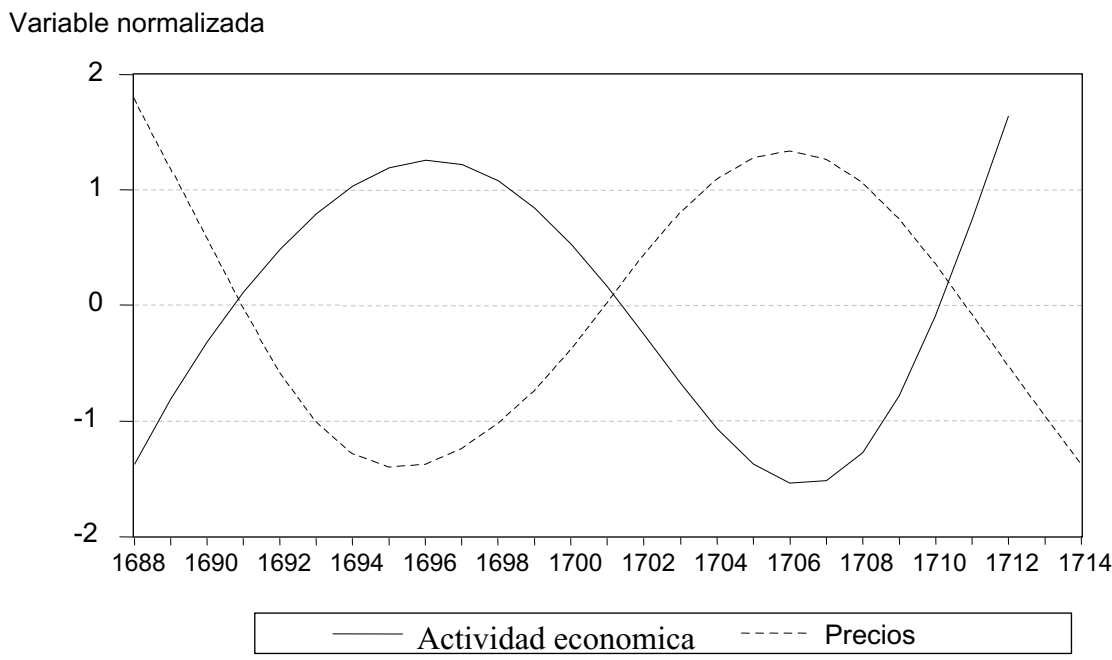

Fuente: TePaske y Klein; Macera

La Figura 10 nos muestra que ello es totalmente coyuntural, al revelar una tendencia creciente en la actividad económica ${ }^{14}$, consistente con las otras regiones. Es claro que la información de las cajas reales para estimar este indicador es más rica que en el caso de los precios, de manera que en un plazo más largo la expansión se sostiene, lo que refuerza el planteamiento inicial de "rechazar la hipótesis de la crisis del siglo XVII" (entre otros, Glave; Klein "The American" y "Fiscalidad").

$14 \quad$ Aquí debemos hacer nuevamente la salvedad de que la serie de datos para la actividad económica tiene una elongación mayor que la correspondiente a los precios. 
Figura 10. Actividad económica (fluctuaciones y tendencias). Trujillo (1688-1712)

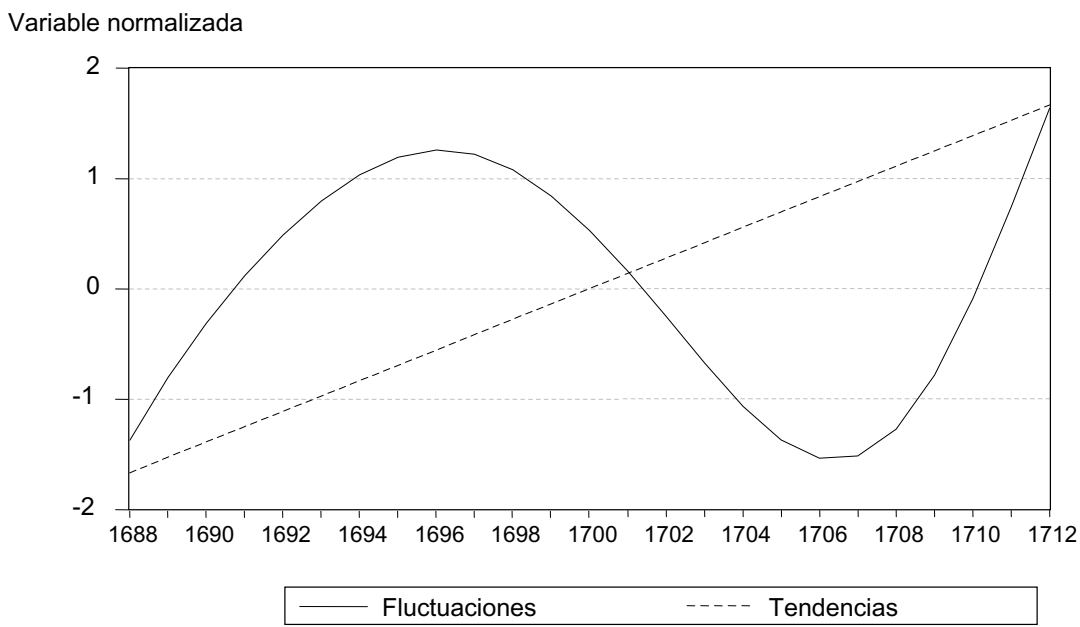

Fuente: TePaske y Klein.

Finalmente, veamos las comparaciones respecto al "circulante". En primer lugar, en lo que se refiere a la actividad económica (Figura 11).

\section{Figura 11. Actividad económica y acuñación. Lima-Santiago-} Trujillo. Tendencias (1600-1713)

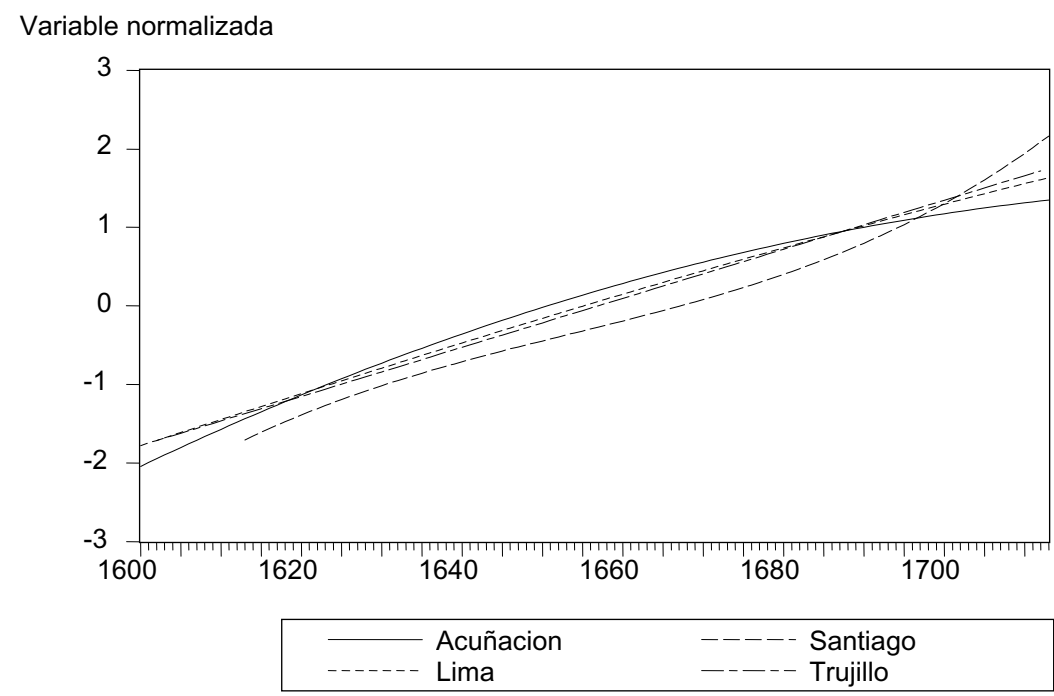

Fuente: Salles y Noejovich (“Santiago"); Noejovich (2000). 
Las cifras de acuñación son netas de las remesas a la Corona, de manera que representan caudales manejados privadamente. Esa evidente correlación, proveniente de dos fuentes independientes, permite sostener la afirmación de que se trataba de una economía en auge, sin ninguna crisis, y que la "independización" de las finanzas respecto a la Corona permitió ese desarrollo, en lo interno y en lo externo, toda vez que esos recursos se utilizaron, también, en la importación (Pease y Noejovich). En todo caso, las quejas sobre la "carencia de liquidez" deben explicarse por el "manejo y control" de esta por parte de las élites (Noejovich, 2006).

Resta abordar la relación entre el "circulante" y los precios, en la cual hemos incluido a Nueva Granada relacionando la "producción de oro" con el índice de precios $^{15}$ (Figura 12).

\section{Figura 12. Producción de oro y precios. Nueva Granada y Bogotá (1652-1700)}

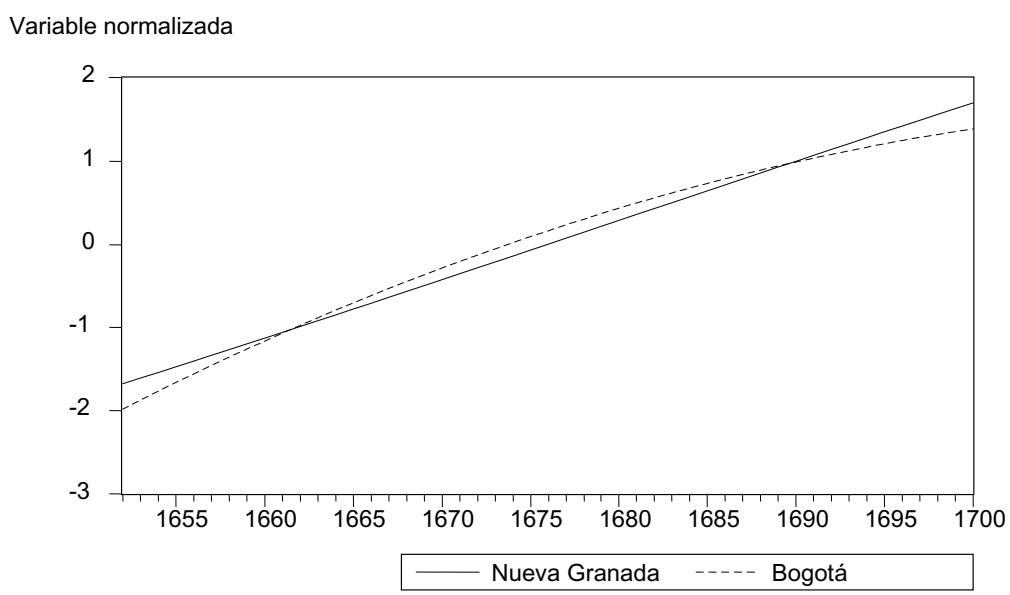

Fuentes: Pardo; Lucena Samoral.

La correlación es casi perfecta ${ }^{16}$ en las tendencias de ambas variables, y congruente con postulados clásicos de la teoría económica, incluso de la época (Bodin). Pero en el caso de los precios no hay correspondencia en Chile respecto a la acuñación en la Caja de Lima; nuevamente, la cuestión del Situado que, como hemos señalado anteriormente, implicaba un movimiento, especialmente en especies y no en metálico (Figura 13).

\footnotetext{
15 Se debe aclarar que el índice es una serie de más de trescientos años, con las lógicas distorsiones por las variaciones de las pautas de consumo.

$16 \rho \cong 1$.
} 


\section{Figura 13. Acuñación y precios. Lima-Santiago-Trujillo. Tendencias (1600-1713)}

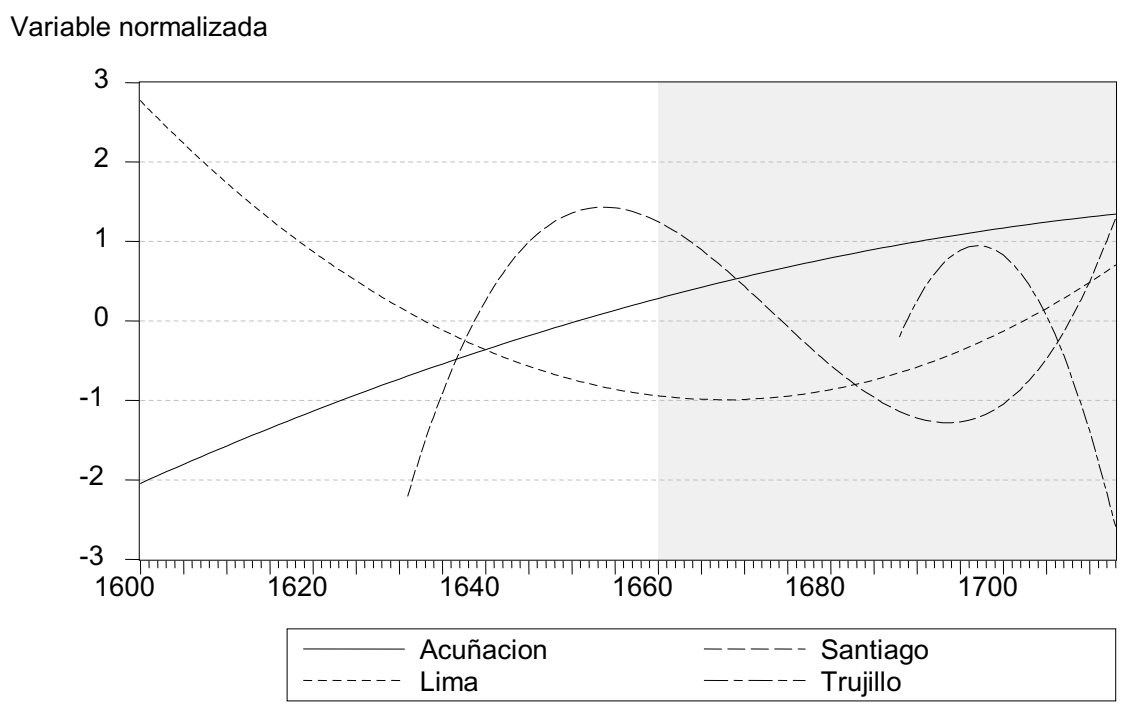

Fuente: elaboración propia.

Consideraciones similares pueden hacerse para Trujillo —una economía esencialmente agraria-, pero, al mismo tiempo, estaríamos reforzando nuestra hipótesis de un "control elitista del circulante". En efecto, en Lima, durante el periodo señalado en la Figura 13 (1600-1713), la correlación entre precios y acuñación es baja ${ }^{17}$, pero al reducir el periodo a 1660-1714, el coeficiente sube notoriamente $^{18}$. ¿Qué significa eso? Que la economía virreinal, dirigida desde Lima, tuvo un vuelco notable en la segunda mitad del siglo XVII. 


\section{Consideraciones finales}

Las cifras son vacuas; no tienen significado propio, sino a través del contexto en que son presentadas. Aquí hemos intentado una presentación coherente por medio de métodos cuantitativos muy simples; no se trata de un ejercicio de verificación y/o rechazo de hipótesis, sino de un análisis ordenado de las cifras disponibles.

Reiteramos, una vez más, que estas últimas muestran un dinamismo en la economía de las tres regiones, también consistente con las referencias neogranadinas, en especial durante el último tercio del siglo XVII. Ensayando una interpretación global, diría que el primer tercio fue el declive del sistema toledano; el segundo tercio, el de adaptación de la política económica a la realidad del espacio correspondiente al Virreinato del Perú, y el último, una consecuencia lógica de este proceso.

Como dije líneas atrás, en todo el proceso coinciden tanto la disminución drástica de las remesas a España como el crecimiento de la actividad económica y el reacomodo del sistema de precios, con la posterior alza de los índices. A través del análisis, puede verse con claridad que la tan mentada "crisis" derivada de la minería potosina no hizo mella en aquellas, sino en el volumen de las remesas a España (Noejovich "La economía"). De manera que podemos postular la existencia de una autonomía económica en el espacio y que tenía concordancia con la relación política entre la Corona e Iberoamérica. Ello puede explicarse por la necesidad de defender las posesiones americanas, recurriendo, para ese fin, a los recursos internos (Salles y Noejovich "La defensa"). 


\section{Bibliografia}

Andrien, Kenneth. Crisis and Decline: The Viceroyalty of Peru in the Seventeenth Century. Albuquerque: University of New Mexico Press, 1985.

Assadourian Sempat, Carlos. El sistema de la economía colonial: mercado interno, regiones y espacio económico. Lima: Instituto de estudios peruanos, 1982.

Bakewell, Peter. Miners off the Red Mountain: Indian Labor in Potosi, 1545-1650. Albuquerque: University of New Mexico Press, 1984.

Bodin, Jean. Los seis libros de la República. Madrid: Aguilar, 1973 [1590].

Cipolla, Carlo. Entre la historia y la economía. Barcelona: Crítica, 1991.

De Ramón, Armando y Larraín, José Manuel. Orígenes de la vida económica chilena: (1659-1808). Santiago: Centro de Estudios Públicos, 1982.

--- "En torno a los precios, a la historia de los precios y a una majadería intelectual". Allpanchis 20.24 (1984) 291-298.

Escalona y Agüero, Gaspar de. Gazophilacium regium perubicum. Madrid: Edición facsimilar, 1775.

Fernández Nadal, Carmen. "La Unión de las Armadas Inglesa y española contra Francia. La Defensa de las Indias en la Guerra de los Nueve Años". Guerra y Sociedad en la Monarquía Hispánica Política, Estrategia y Cultura en la Europa Moderna (1500-1700). García Hernan, E. y Maffi, Davide. ed. Madrid: Laberinto, Instituto de Cultura, Consejo Superior de Investigaciones Científicas, 2006.

Glave, Luis Miguel. "El virreinato peruano y la llamada 'crisis general' del siglo XVII". Las crisis en la historia del Perú. Bonilla, Heraclio. eds. Lima: Centro Latinoamericano de Historia Económica y Social, Fundación Federico Ebert, 1986.

Klein, Herbert. The American Finances of the Spanish Empire: Royal Income and Expenditures in Colonial México, Perú, and Bolivia, 1680-1809. Albuquerque: The University of New Mexico Press, 1998.

--- Fiscalidad real y gastos de gobierno: el virreinato del Perú 1680-1809. Lima: Instituto de estudios peruanos, 1994. 
Lazo García, Carlos. Economía colonial y régimen monetario. Perú siglos XVIXIX. Lima: Banco Central de Reserva, 1992.

Lucena Samoral, Manuel. ed. "Fuentes para el estudio de la fiscalidad colonial: Las cajas auríferas neogranadinas en el siglo XVI. La producción de oro en el Nuevo Reino de Granada a través de las Cajas Reales". Estudios de historia Social y Económica de América 8 (1992).

Macera, Pablo. Los precios del Perú. Siglos XVI-XIX: fuentes. Lima: Banco Central de reserva del Perú, 1992.

Malamud Rickles, Carlos Daniel. Cádiz y Saint Malo en el comercio colonial peruano (1698-1725). Cádiz: Diputación Provincial, 1986.

Mellafe, Rolando. Historia social de Chile y América. Santiago: Universitaria, 1986.

Moreyra Paz Soldan, Manuel. La moneda colonial en el Perú. Lima: Banco Central de reserva del Perú, 1980.

Noejovich Chernoff, Héctor Omar. Los albores de la economía americana. Lima: Fondo Editorial Pontificia Universidad Católica del Perú, Fondo Editorial, 1996.

--- "Los usos monetarios y la segmentación social: un ensayo diacrónico sobre la historia monetaria del virreinato y la republica del Peru (siglos xvi-xvii, xix y xx)". Cambio Institucional e Historia Económica. Pujol Andreu, Josep; Fatjó Gómez, Pedro y Escandell Tur, Neus. eds. Barcelona: Universidad Autónoma de Barcelona, Departamento de Economia e Historia Económica, 1996.

--- "La economía del virreinato del Perú bajo los Habsburgo". Boletín del Instituto Riva Agüero 24, (1997).

--- "Nivel de precios y actividad económica: un ensayo económico en el virreinato del Perú”. Economía 23.46 (2001).

--- "El consumo de azogue ¿Indicador de la corrupción del sistema colonial en el virreinato del Perú? (siglos XVI-XVII)”. Fronteras de la Historia 7 (2002). 
Pardo, Alberto. Geografia Económica y Humana de Colombia. Bogotá: Tercer Mundo, 1972.

Pease, Franklin y Noejovich, Héctor. "La cuestión de la plata en los siglos XVIXVII". Histórica 24 (2000) [1992].

Romano, Ruggiero. "Precios, historia de los precios y deshonestidad". Allpanchis 22 (1983).

Salles, Estela y Noejovich, Héctor. "Santiago y Buenos Aires: la actividad económica en la frontera sur del virreinato del Perú (siglo XVII)". Economía 23.45 (1999).

--- "La defensa del virreinato del Perú: aspectos políticos y económicos. (1560-1714)". Ponencia presentada en las XXI Jornadas de Historia Económica. Caseros, 2008.

Suarez Espinosa, Margarita. Desafios transatlánticos. Mercaderes, banqueros y el estado en el Perú vírreinal 1600-1700. Lima: Fondo Editorial Pontificia Universidad Católica del Perú, Instituto Francés de Estudios Andinos, Fondo de Cultura Económica, 2001.

Tepaske, John y Klein, Herbert. The Royal Treasuries of Spanish Empire in America. Durham: Duke University Press, 1982.

Vargas Cariola, Juan Eduardo. "Financiamiento del ejército de Chile en el siglo XVII". Historia 19 (1984): 159-202.

Walker, Geoffrey. Spanish politics and imperial trade, 1700-1789. Londres: Mac Millan, 1979.

Fecha de recepción: 30 de mayo de 2008

Fecha de aprobación: 25 de septiembre de 2008 


\section{Anexo I. Convenciones metodológicas}

Los detalles matemáticos están consignados en el Anexo III. Brevemente señalamos las principales características.

1. Los ejercicios fiscales irregulares ${ }^{1}$ fueron promediados según los años comprendidos, y aquellos que no llegaban a dos años fueron imputados al año de cierre.

2. Los años faltantes fueron completados por interpolación exponencial ${ }^{2}$.

3. El problema de la unidad monetaria fue resuelto convirtiendo las cifras en pesos de a ocho. Para ello, se utilizó el coeficiente 1,65 para el peso ensayado y de 2,05 para el peso oro ${ }^{3}$.

4. Los datos fueron convertidos a logaritmos, para estimar las tendencias en funciones lineales ${ }^{4}$ y facilitar el cálculo de las medias geométricas ${ }^{5}$ utilizadas en el cálculo de los índices de precios.

5. Las figuras están presentadas en pesos de a ocho, en forma normalizada ${ }^{6}$, con el propósito de comparar visual y rápidamente fluctuaciones y tendencias entre magnitudes de diferente orden.

6. El año inicial es 1562 y el año final, 1714. En todos los casos, las tendencias fueron calculadas dentro de ese intervalo ${ }^{7}$.

7. El objetivo del análisis fue separar las tendencias de las variaciones cíclicas ofluctuaciones ${ }^{8}$.

1 Especialmente en la Caja de Lima, el cierre de los ejercicios se hacía coincidir con los envíos de remesas a Castilla.

2 Que supone una tasa de crecimiento y/o decrecimiento constante entre los extremos conocidos.

3 Anteriormente he realizado un análisis sobre las equivalencias monetarias en el sistema colonial en el siglo XVI (Noejovich, "Los usos" 204). Por otra parte, el documento confeccionado por Lamberto de Sierra (Moreyra Paz Soldán 275) señala las variaciones del valor de los pesos ensayados a finales del siglo XVII; así mismo, TePaske y Klein (xviii) hacen hincapié en el alza del peso oro en la segunda mitad del siglo XVII. Para este último, dado que sobre los totales de recaudación en las cajas reales el oro representaba apenas el 2\% (Pease y Noejovich), sus variaciones no son significativas. Para el peso ensayado, aumentar el valor de conversión implicaría aumentar la recaudación y la actividad económica que fue calculada sobre esa base; lo que no alteraría mayormente nuestras conclusiones. Finalmente, los datos de precios están indicados en las fuentes en pesos de a ocho.

4 De fácil derivación, a los efectos de calcular las tasas de variación de las distintas magnitudes.

5 En lugar de multiplicar las magnitudes y extraerles la raíz del orden correspondiente, basta con sumar y dividir.

6 Respecto a la media y la desviación normal $(\sigma)$.

7 Esto significa que para $1562, t=1$, y para $1714, t=153$, en todas las series.

8 Hemos seguido el método tradicional de morigerar, primero, la serie con base en medias móviles - cinco años - y luego de ésta, calcular la tendencia por ajuste según el método de los mínimos cuadrados. Trabajando con logaritmos, ello implica asumir interdependencia entre la tendencia y las variaciones cíclicas. 
8. Construimos un índice de actividad económica sobre la base de las cuentas fiscales, que si bien tienen sus problemas ${ }^{9}$, en el caso de la economía colonial son las mejores fuentes disponibles, aunque distan mucho, por supuesto, de ser óptimas ${ }^{10}$.

\section{Anexo II. Cajas reales (1560-1714). Clasificación global de los ingresos}

\begin{tabular}{|l|l|}
\hline \multicolumn{1}{|c|}{ Rubro } & \multicolumn{1}{c|}{ Concepto } \\
\hline Cuentas fiscales & $\begin{array}{l}\text { Son aquellos ingresos que representan impuestos, tasas, contribuciones y/o ventas rea- } \\
\text { lizadas por los monopolios estatales. }\end{array}$ \\
\hline Cuentas financieras & $\begin{array}{l}\text { Corresponden a los movimientos por transferencias entre cajas (situados y venidos), } \\
\text { alcances, depósitos, censos, empréstitos, juros y afines. }\end{array}$ \\
\hline Cuentas por aplicar & $\begin{array}{l}\text { Existen denominaciones que prima facie no se pueden identificar claramente, como } \\
\text { enterados, extraordinarios, caudal existente, etc. }\end{array}$ \\
\hline Cuentas de ajuste & $\begin{array}{l}\text { Creadas especialmente para confeccionar un balance consolidado de las cajas reales, } \\
\text { de acuerdo con los principios de la partida doble. }\end{array}$ \\
\hline
\end{tabular}

Fuente: Noejovich (2001).

\section{Anexo III ${ }^{11}$}

\section{Criterio de interpolación}

Sea $a t=$ dato $a$ en el periodo $t$. El problema es:

la serie de datos varía de $t_{o}$ a $t_{z}$, pero contiene un intervalo desconocido entre $t_{m} \mathrm{y} t_{n}$, donde debemos completar at datos, tal que $n=m+s+1$

$$
\text { Luego, }
$$

$$
\left\{a t_{o^{\prime}} a t_{1}, a t_{2}, a t_{3}, \ldots \ldots . ., a t_{m}, \ldots \ldots \ldots \ldots . . a t_{s}, a t_{n}, a t_{n+1}, a t_{n+2}, \ldots \ldots . . a t_{z}\right\}
$$

Para efectos de la interpolación calculamos:

$$
r=\left[\left(a t_{n} / a t_{\mathrm{m}}\right)^{l /(n-m)}\right]-1
$$

9 Cipolla (55) cita las fuentes fiscales como ejemplo de fuente verdadero, pero con contenido falso.

10 El sistema consiste en aplicar coeficientes a los ingresos fiscales. Para un detalle del procedimiento, véase el Anexo III.

11 Tomado de Noejovich (2000). 
Siendo,

$$
\begin{gathered}
a t_{m+1}=a t_{m}(1+r) \\
a t_{m+2}=a t_{m+1}(1+r) \\
a t_{m+s}=a t_{m+s-1}(1+r)
\end{gathered}
$$

\section{Criterios sobre las series cronológicas}

Las series cronológicas se definen por cuatro componentes:

$$
\begin{gathered}
T_{t}=\text { tendencia } \\
C_{t}^{=}=\text {fluctuaciones } \\
S_{t}=\text { estacionalidad } \\
E_{t}=\text { perturbaciones accidentales }
\end{gathered}
$$

Simbólicamente:

$$
Y_{t}=f\left(T_{t} ; C_{t} ; S_{t} ; E_{t}\right)
$$

Respecto a la relación entre los componentes de las series, se pueden asumir dos hipótesis:

1. Que es aditiva. Los componentes de la serie son independientes.

2. Que es multiplicativa. Los componentes de la serie son independientes.

En nuestro caso, hemos adoptado la última hipótesis, que facilita su operatibilidad por la conversión en logaritmos:

$$
\ln Y_{t}=\ln T_{t}+\ln C_{t}+\ln S_{t}+\ln E_{t}
$$

\section{Cálculo del índice de precios}

Dado que los datos están tomados en logaritmos, la adición, año a año, de los datos de las tendencias de cada bien incluido representa una media geométrica de estos. Sea:

$$
\begin{gathered}
I_{t}=\text { índice de precios para cada } t \\
T_{i t}=\text { tendencia del bien } i \text { para cada } t \\
N_{t}=\text { cantidad } i \text { para cada } t
\end{gathered}
$$

Entonces:

$$
I_{t}=\Sigma T_{i t} / N_{t}
$$


Anexo IV. Actividad económica

\section{Análisis de los criterios para el cálculo de los coeficientes Criterios de evaluación}

\section{General}

Impuestos con tasa porcentual definida: volumen de actividad económica $=$ recaudación tributaria $x$ inversa de la tasa porcentual.

Simbólicamente

$V=$ volumen de actividad económica

$R=$ recaudación tributaria
Luego:

$V=R / i$

$i=$ tasa porcentual

\section{Especial}

\section{Tabla 1. Criterios específicos para cada sector}

\begin{tabular}{|c|c|}
\hline Sector & Criterio \\
\hline Comercio exterior & $\begin{array}{l}\text { La base de estimación fue el almojarifazgo. Las tasas consideradas fueron: 7,5\%, 5\% y } \\
2,5 \% \text {. Para los casos que carecen de identificación de tasa se tomó al } 5 \% \text {. }\end{array}$ \\
\hline Comercio interior & $\begin{array}{l}\text { El volumen está en relación con la recaudación de los impuestos de alcabala y de unión } \\
\text { de armas, cuyas tasas eran del } 2 \% \text { cada uno (Escalona y Agüero 150). }\end{array}$ \\
\hline Estancos & $\begin{array}{l}\text { Fueron considerados como unidad, dado que la actividad económica es equivalente al } \\
\text { ingreso mismo. }\end{array}$ \\
\hline Eclesiástico & $\begin{array}{l}\text { Las vacantes, diezmos y novenas sirvieron como base de estimación en las proporcio- } \\
\text { nes indicadas por Escalona y Agüero (239); igualmente se hizo con la mesada. La bula } \\
\text { de Santa Cruzada fue considerada en proporción } 2: 1(1775: 244) \text { y los demás ingresos } \\
\text { (expolio, breviarios, etc.), en proporción } 1: 1 \text {. }\end{array}$ \\
\hline Minero & Calculado con base en quintos $(20 \%)$, diezmos $(10 \%)$, sesmos $(16,66 \%)$ y cobos. \\
\hline Funcionarios & $\begin{array}{l}\text { Para estimar los ingresos de estos los criterios fueron: } \\
\text { (a) Según los vendibles y renunciables. Hemos calculado, primero, un "valor proba- } \\
\text { ble esperado por la Corona" de } 2,4 \text { el monto ingresado por este ítem, suponiendo dos } \\
\text { transferencias (Escalona y Agüero } 167 \text { ). Este "valor probable esperado por la Corona" } \\
\text { se asumió como valor presente del cargo u oficio, correspondiente a un valor futuro". } \\
\text { Resultó un coeficiente equivalente a } 3,9093 \text { veces el monto ingresado a la Caja Real } \\
\text { por este concepto. } \\
\text { (b) Según las medias annatas. Asumimos que la duración máxima de los cargos era de } \\
\text { cuatro años, ya que, como mínimo, eran dos años (Andrien } 48 \text { ), y existían reduccio- } \\
\text { nes cuando la duración fuese menor (Escalona y Agüero, 1775, pássim). Esto significa } \\
\text { considerar un semestre cada ocho semestres; el ingreso estimado está en la proporción } \\
8: 1 . \\
\text { (c) Los ítems sin identificación precisa fueron prorrateados en función de los identifica- } \\
\text { dos. Esto arrojó un promedio de 5,552 veces*. }\end{array}$ \\
\hline
\end{tabular}


Tabla 1. Criterios específicos para cada sector (Continuación)

\begin{tabular}{|l|l|}
\hline \multicolumn{1}{|c|}{ Sector } & \multicolumn{1}{c|}{ Criterio } \\
\hline Penalidades & $\begin{array}{l}\text { Fueron considerados como unidad, asumiendo que la actividad económica es equiva- } \\
\text { lente al ingreso mismo. }\end{array}$ \\
\hline Tierra & $\begin{array}{l}\text { Fueron considerados como unidad, asumiendo que la actividad económica es equiva- } \\
\text { lente al ingreso mismo*** }\end{array}$ \\
\hline Tributo & $\begin{array}{l}\text { Nuestra estimación surge del promedio de dos criterios: } \\
\text { (a) Anteriormente (Noejovich, 2006 218), en función de las jornadas de trabajo para } \\
\text { producir el tributo, estimamos en Huánuco un promedio de 41,8825 jornadas de trabajo } \\
\text { por unidad doméstica****, que, distribuidas individualmente, con base en la capacidad } \\
\text { individual anual de 260 días/hombre, arrojan como resultado una incidencia del tributo } \\
\text { del 16,1\%; por ende, el coeficiente que se va a utilizar es 6,2078. } \\
\text { (b) Bakewell (105) refiere un tributo de 32 pesos de a ocho por mitayo. En Noejovich } \\
\text { (1997), asumiendo que el mitayo trabajaba como mingado el resto del tiempo que no } \\
\text { concurría a la mita ordinaria, calculamos un salario anual de 215,83 pesos de a ocho; } \\
\text { la relación entre ambas magnitudes es 6,7447. El promedio resultante es de 6,476, } \\
\text { coeficiente que se aplicó a los tributos indígenas propiamente dichos, al efectuar las } \\
\text { proporciones correspondientes, en los casos ingresados como quintos y mitades. }\end{array}$ \\
\hline
\end{tabular}

* Semejante a la imposición de un censo al 5\% anual, pero con un plazo de diez años.

** Un cálculo semejante para Potosí (Noejovich "La economía") arrojó un promedio de 4,7211; esto implicaría asumir que los cargos y oficios eran más rentables en Lima.

*** Admito que este supuesto es demasiado "rígido", pero, por el momento, carezco de base alguna para evaluar "qué representaban las composiciones de tierra en términos de volumen de actividad económica".

**** La unidad doméstica tiene una capacidad de fuerza de trabajo en función de sus integrantes (mujeres, hijos, viudas, etc.) y el promedio está medido en relación con la magnitud de esta y no solamente del esfuerzo individual. La "jornada de trabajo" es la que trabaja un hombre en un día, sin importar las horas dedicadas (Noejovich, 1996 81).

Fuente: Noejovich (2001). 